\title{
Hypertension and lifestyle modification: how useful are the guidelines?
}

Hypertension is a significant risk factor for coronary artery disease and stroke, a leading cause of death and disability worldwide, and a major risk for dementia, chronic kidney disease, coronary heart disease, and heart failure. The prevalence of hypertension-related events is increasing, with the majority occurring among pre-hypertensives (120-139 mmHg systolic; $80-89 \mathrm{mmHg}$ diastolic) and stage1 hypertensives (140-159 mmHg systolic; 90-99 mmHg diastolic). In the UK it was estimated that there are 62000 needless deaths per year due to uncontrolled blood pressure, ${ }^{1}$ with the condition presenting a particular problem among Asian immigrant communities.

There has been some discussion in this Journal of the helpfulness of guidelines for a number of conditions. One editorial has highlighted the possible mismatch between guidelines and internationallyagreed quality criteria, the lack of a concise set of concrete recommendations, and a risk of bias in that, notwithstanding the availability of scientific evidence, the guidelines may in fact largely reflect local culture or personal viewpoints. ${ }^{2}$ It is with this in mind that we intend to examine the guidelines for control of hypertension with respect to diet/behavioural modification.

\section{LIFESTYLE MODIFICATION ADVICE IN THE GUIDELINES}

The hypertension clinical guideline from the National Institute for Health and Clinical Excellence (NICE) usefully recommends regular aerobic exercise and reduction of salt, alcohol, and smoking, and advocates 'healthy, low-calorie diets' for 'overweight individuals with raised blood pressure', but gives a rather negative comment about its 'modest effect' and the unexplained variability of effect in trials. ${ }^{3}$ There is no explanation of what a healthy, low-calorie diet comprises, and the overall impression is that the writers do not consider dietary intervention to be relevant to those of normal weight or those without hypertension, and that even in overweight hypertensives it will not have much effect.

This is in stark contrast to the far more comprehensive British Hypertension Society (BHS) guidelines, ${ }^{4}$ which largely concur with guidance from the World Health Organization, ${ }^{5}$ European Society of Cardiology, ${ }^{6}$ American Society of Hypertension, ${ }^{7}$ the American Heart Association, ${ }^{8}$ and the American Medical Association. ${ }^{9}$ These guidelines recognise the wealth of quality clinical trials showing unequivocally that diet and behavioural interventions can have a significantly beneficial effect on hypertension, which is not confined to the overweight.

BHS guidelines state that advice should be provided for prevention as well as treatment of hypertension and should be given to pre-hypertensives and those with a strong family history. They point out that effective lifestyle modification can lower blood pressure by at least as much as a single antihypertensive drug. Even a $2 \mathrm{mmHg}$ decrease in diastolic blood pressure has been found to reduce hypertension prevalence by $17 \%$, risk of coronary heart disease by $6 \%$, and stroke by $15 \% .^{10}$

In addition to the NICE recommendations, the BHS also advocates maintenance of normal body weight, consumption of a diet rich in fruit and vegetables, and reduced total and saturated fat. They make the point that these interventions can reduce the need for drug therapy, enhance the effect of antihypertensive drugs, reduce the need for multiple drug regimens, and favourably influence overall cardiovascular risk. ${ }^{4}$ The international guidelines ${ }^{5-9}$ advocate diet/behavioural modification at every stage, both before drug therapy in prehypertension or uncomplicated stage-1 hypertension, as well as for high-risk patients and those on medication. They also specifically recommend adoption of the Dietary Approaches to Stop Hypertension (DASH) eating plan.

\section{PROVEN LIFESTYLE MODIFICATIONS}

The DASH diet is low in total and saturated fat, red meat, sugar, sugary drinks, and refined carbohydrates, but high in fruits, vegetables, whole grains, fish, poultry, and low-fat dairy products. The DASH diet has been found to lower weight, heart rate, risk of type 2 diabetes, C-reactive protein, apolipoprotein B, and homocysteine and is associated with a lower incidence of heart failure, all-cause mortality, and stroke. ${ }^{11-12}$

The Optimal Macronutrient Intake Trial to Prevent Heart Disease (or OMNIHeart trial) found that replacement of some of the DASH diet's carbohydrate intake with either protein (50\% from plant sources) or unsaturated fat (mainly monounsaturated, found in olives and olive oil) could reduce blood pressure, low-density lipoprotein, homocysteine, and coronary heart disease risk even further. ${ }^{13-14}$

The PREMIER trial found that the DASH diet combined with alcohol and salt reduction, weight loss, and aerobic exercise achieved a reduction of $14.2 / 7.4 \mathrm{mmHg}$ among hypertensives, while hypertension prevalence fell over a period of 6 months from $38 \%$ to $12 \% .^{15}$ Salt reduction, possibly the single most important hypotensive measure, involves staying away from processed foods, regularly checking food labels for salt content, and using herbs or spices for flavour. ${ }^{16}$

Other successful approaches include the Mediterranean diet, essentially the DASH diet with low sodium and with added garlic and increased omega-3containing fish: both powerful hypotensives. The Mediterranean diet is also inversely associated with diabetes, obesity, and hypercholesterolaemia among high-risk patients, and was recently advocated by the Mayo Clinic for women's heart health. Drinking green tea and modest quantities of red wine are also effective. ${ }^{17-18}$ 


\section{OPTIMISING THE CHANCE OF SUCCESS}

It is generally agreed that the greatest chance of success with diet and behavioural modification is achieved with clear written and verbal explanations, a chance for the patient or their carer to ask questions and talk through potential problems, regular monitoring and followup, and a support group to encourage compliance. Referral to a dietician, nutritionist, or experienced nurse would clearly be beneficial.

A recent UK study showed that hypertension management delivered by practice nurses could provide improved clinical outcomes. ${ }^{19}$ Where these resources are not available, a physician needs to be able to give patients the basic information (Box 1). Although some patients are reluctant to accept that their lifestyle choices have contributed to their condition and may refuse advice to change, the authority and credibility of the physician should not be underestimated. The American Heart Association guidelines specifically recognise that physicians can have a powerful influence on their patients' willingness to make changes. ${ }^{8}$

\section{BENEFITS OF LIFESTYLE MODIFICATION}

The BHS and international guidelines advocate diet and behavioural modification with all patients, regardless of weight,

\section{Box 1. Diet and behavioural modifications to control hypertension \\ - Stop smoking \\ - Reduce:}

Total and saturated fat

Red meat

Sugar, sugary drinks

Refined carbohydrates

Salt

Alcohol (except modest amounts of red wine)

Weight

- Increase:

Fruits, vegetables, whole grains Fish and poultry Low-fat dairy products

Olives and olive oil

Garlic

Aerobic exercise severity of hypertension, or intake of medication. The advantages include a significant drug cost reduction, a beneficial effect on other conditions, such as diabetes and hypercholesterolaemia, and avoidance or delay of drug treatment with its potential for adverse effects.

In an age when patients are increasingly educating themselves as to the side effects of drugs and possible alternative approaches, a growing number may be willing to take more responsibility for their health and institute the necessary changes, but merely require approval and direction from their doctor. GPs should take every opportunity to put pressure on the government and food manufacturers to champion a healthy lifestyle and reduce unhealthy elements in processed foods.

\section{Rachel Nicoll,}

Canterbury Christ Church University, UK, and Heart Centre and Department of Public Health and Clinical Medicine, Umeå, Sweden.

\section{Michael Y Henein,}

Canterbury Christ Church University, UK, and Heart Centre and Department of Public Health and Clinical Medicine, Umeå, Sweden.

\section{Provenance}

Commissioned; not peer reviewed.

\section{REFERENCES}

1. He FJ, MacGregor GA. Cost of poor blood pressure control in the UK: 62,000 unnecessary deaths per year. J Hum Hypertens 2003; 17(7): 455-457.

2. Grol R, van Weel C. Getting a grip on guidelines: how to make them more relevant to practice. Br J Gen Pract 2009; 59(562): e143-144.

3. National Institute for Health and Clinical Excellence. NICE clinical guideline 34 Hypertension: management of hypertension in adults in primary care (partial update of NICE clinical guideline 18). London: NICE, 2006. http://www.nice.org.uk/nicemedia/pdf/CG034NICEgui deline.pdf (accessed 11 Nov 2010).

4. Williams B, Poulter NR, Brown MJ, et al. Guidelines for management of hypertension: report of the fourth working party of the British Hypertension Society, 2004-BHS IV. J Hum Hypertens 2004; 18(3): 139-185.

5. Whitworth JA, World Health Organisation, International Society of Hypertension Writing Group. 2003 World Health Organization (WHO)/International Society of Hypertension (ISH) statement on management of hypertension. J Hypertens 2003; 21(11): 1983-1992.

6. Erdine S, Ari O, Zanchetti A, et al. ESH-ESC guidelines for the management of hypertension. Herz 2006; 31(4): 331-338.

7. Appel LJ; American Society of Hypertension Writing Group, Giles TD, et al. ASH Position Paper: dietary approaches to lower blood pressure. J Clin Hypertens 2009; 11(7): 358-368.

8. Appel LJ, Brands MW, Daniels SR, et al. Dietary approaches to prevent and treat hypertension: a scientific statement from the American Heart
Association. Hypertension 2006; 47(2): 296-308.

9. Chobanian AV, Bakris GL, Black HR, et al. The Seventh Report of the Joint National Committee on Prevention, Detection, Evaluation, and Treatment of High Blood Pressure: the JNC 7 report. JAMA 2003; 28(19): 2560-2572.

10. Cook NR, Cohen J, Hebert PR, et al. Implications of small reductions in diastolic blood pressure for primary prevention. Arch Intern Med 1995; 155(7): 701-709.

11. Chen ST, Maruthur NM, Appel LJ. The effect of dietary patterns on estimated coronary heart disease risk: results from the Dietary Approaches to Stop Hypertension (DASH) trial. Circ Cardiovasc Qual Outcomes 2010; 3(5): 484-489.

12. Craddick SR, Elmer PJ, Obarzanek E, et al. The DASH diet and blood pressure. Curr Atheroscler Rep 2003; 5(6): 484-491.

13. Swain JF, McCarron PB, Hamilton EF, et al. Characteristics of the diet patterns tested in the optimal macronutrient intake trial to prevent heart disease (OMNIHeart): options for a heart-healthy diet. J Am Diet Assoc 2008; 108(2): 257-265.

14. Miller ER 3rd, Erlinger TP, Appel LJ. The effects of macronutrients on blood pressure and lipids: an overview of the DASH and OMNIHeart trials. Curr Atheroscler Rep 2006; 8(6): 460-465.

15. Appel LJ, Champagne CM, Harsha DW, et al. Effects of comprehensive lifestyle modification on blood pressure control: main results of the PREMIER clinical trial. JAMA 2003; 289(16): 2083-2093.

16. Mahtani KR. Simple advice to reduce salt intake. $\mathrm{Br} J$ Gen Pract 2009; 59(567): 786-787.

17. Pérez-López FR, Chedraui P, Haya J, Cuadros JL. Effects of the Mediterranean diet on longevity and age-related morbid conditions. Maturitas 2009; 64(2): 67-79.

18. Núñez-Córdoba JM, Valencia-Serrano F, Toledo E, et al. The Mediterranean diet and incidence of hypertension: the Seguimiento Universidad de Navarra (SUN) Study. Am J Epidemiol 2009; 169(3): 339-346.

19. Griffiths P, Murrells T, Maben J, et al. Nurse staffing and quality of care in UK general practice: crosssectional study using routinely collected data. $\mathrm{Br} \mathrm{J} \mathrm{Gen}$ Pract 2010; 60(570): 36-48.

DOI: 10.3399/bjgp10X544014

\section{ADDRESS FOR CORRESPONDENCE}

Professor Michael Y Henein

Department of Public Health and Clinical

Medicine, and Heart Centre, Umeå

University, SE-90187, Sweden.

E-mail: Michael.henein@medicin.umu.se 